\title{
Abstract: With Joyful Flow-The Dual Information Processing Effect of Pragmatic and Hedonic User Experience on Brand Attachment
}

\author{
Steffen Schmidt, Sascha Langner, Nadine Hennigs, Levke Albertsen, \\ Evmorfia Karampournioti, and Matthias Rothensee
}

\begin{abstract}
A modern management of user experience in the current digital age requires a profound knowledge of its main elements and consequences. With regard to the measurement of user experience, science and business practice often refer to conventional, explicit measures such as self-reports. However, social psychology and neuroeconomics argue that most mental processes are of so-called implicit nature, taking place hidden in the unconscious mind. With that said, the current research focuses on the explicit and implicit impact of user experience on brandrelated behavior. For that reason, a conceptual model integrating explicit and implicit information processes of hedonic and pragmatic user experience is derived. Furthermore, a new measurement instrument incorporating explicit and implicit measures of user experience is developed. The empirical results of the conducted online study provide evidence for a satisfying performance of the presented conceptual model and the related user experience measures. In detail, findings indicate significant effects of user experience on brand attachment both on an explicit and implicit information processing level.
\end{abstract}

\footnotetext{
S. Schmidt $(\bowtie) \bullet$ S. Langner $\bullet$ N. Hennigs $\bullet$ L. Albertsen $\bullet$ E. Karampournioti Leibniz University of Hannover, Hannover, Germany e-mail: schmidt@m2.uni-hannover.de; langner@m2.uni-hannover.de; hennigs@m2. uni-hannover.de; albertsen@m2.uni-hannover.de; karampournioti@m2.uni-hannover.de

M. Rothensee eye square $\mathrm{GmbH}$, Berlin, Germany

e-mail: rothensee@eye-square.com
} 